\title{
ARTICLE
}

\section{Climate change and the assemblages of school leaderships}

\author{
Thomas Everth*(i) and Ria Bright (i) \\ School of Education, University of Waikato, Hamilton, New Zealand \\ ${ }^{\star}$ Corresponding author. E-mail: thomas.everth@gmail.com
}

(Received 24 August 2021; revised 24 January 2022; accepted 25 January 2022; first published online 21 February 2022)

\begin{abstract}
Anthropogenic climate change and the necessary transformation of society to mitigate its consequences constitutes an unprecedented educational challenge. Responding to the climate emergency and to society's awakening climate activism generates a complex situation for school leadership in particular. Here, we report findings from our research with climate activist students and teachers in Aotearoa New Zealand. We argue that school leadership plays a crucial role in enabling student and teacher agency and the development of effective Climate Change Education in schools. We utilise assemblage thinking, situating this within the new materialisms, to conceptualise schools and their leadership as dynamic assemblages, and we discuss teacher and student experiences as actors across such assemblages. We conclude that deterritorialisation and decoding of educational institutions and their leadership practices can promote and enable education to become a driver of the cultural transformation of society that the climate emergency mandates.
\end{abstract}

Keywords: assemblage theory; Climate Change Education; school leadership; new-materialism

\section{Introduction}

Anthropogenic climate change is the most profound contemporary challenge for the future of humans, nonhumans, and ecosystems (Carter, 2019; IPCC, 2018; Ripple, Wolf, Newsome, Barnard \& Moomaw, 2019; Schellnhuber et al., 2016; Steffen et al., 2018). Climate change compels us to re-conceptualise the relationship between humanity and the rest of the more-than-human worlds we inhabit. It injects urgency into the turn towards new materialist ontologies and the project of bridging the divide between discourse and materiality, the social and the natural sciences, and the interrogation of relationships of power and politics, with profound implications for education (Barad, 2007; Ellenzweig, 2017; Reid, 2019; Zembylas, 2017). Wide-ranging and sustained educational initiatives will be required to prepare citizens for the informed decision-making and action-taking needed to meet the challenges we face. Education is central to the generation as well as the reproduction of culture, social patterns and strata. We refer here to Nash's (1990) discourse of Bourdieu's extensive work and theories. Nash (1990) highlights Bourdieu's thesis of schools as a culturally reproductive and 'conservative force' (p. 435) in society, while recognising the autonomous powers that schools have, in principle, to 'shape consciousness, over and above the power of the family' (p. 435). And with respect to the dominant forces of society and the formation of culture, Webb, Schirato, and Danaher (2020) paraphrase Bourdieu in saying that 'something becomes "culture" because it is in someone's (or some institution's) interests for this to be so' (p. 155). Education aids the reproduction of the dominant culture. 


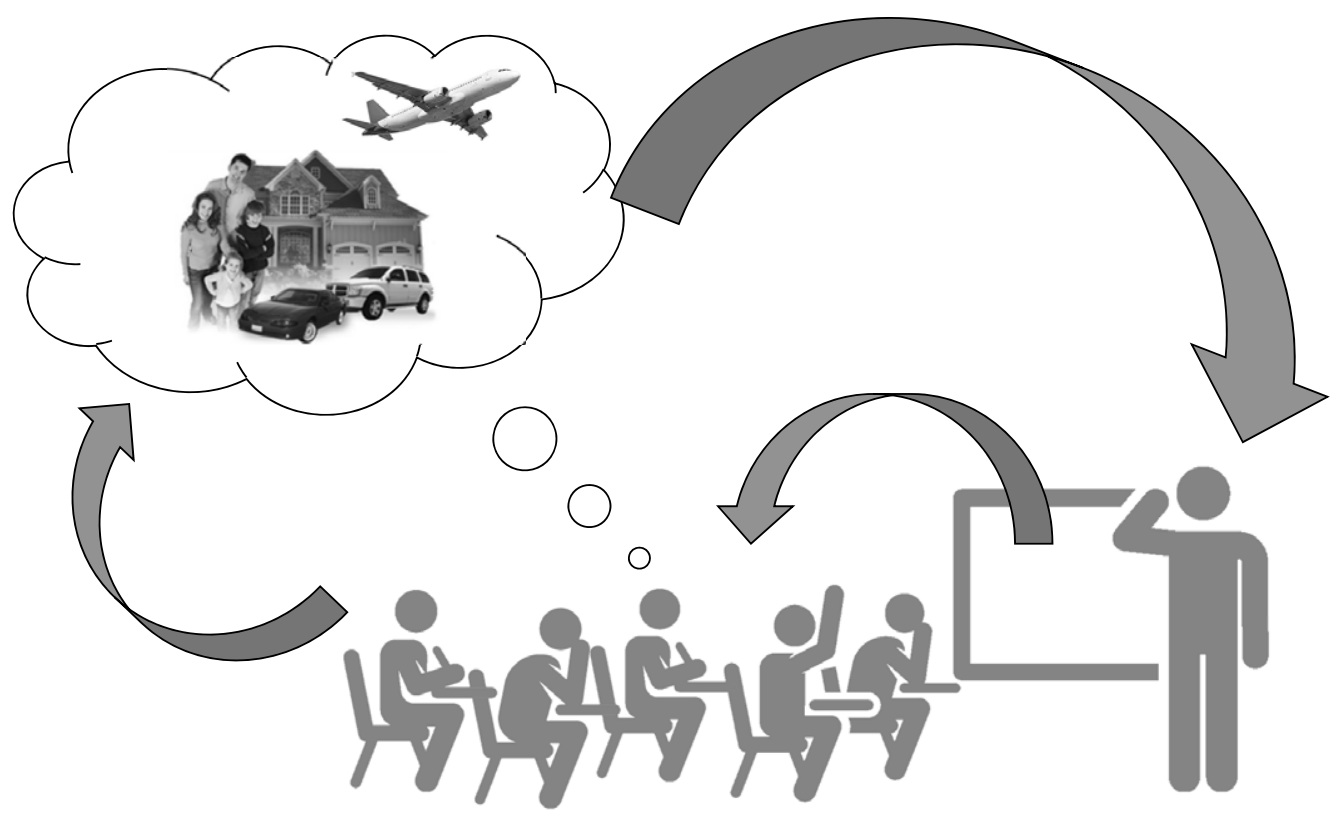

Figure 1. Traditionally, schools function as systems of enculturation and cultural reproduction.

Standing at the precipice of the apocalyptic futures evoked by the failings of predominant Western neoliberalist culture we argue with Irwin (2020), that cultural reproduction can no longer continue (Figure 1) and that instead education must reclaim its autonomy to transform itself into a generator of sustainability culture and driver of cultural transformation. Education can become a catalyst for positive change to move society towards potential climate-friendly futures. To do so, the generation of agency within educational institutions to change societal attitudes, behaviours and expectations is paramount. We here refer also to the book Touchstones for Deterritorializing Socioecological Learning (Cutter-Mackenzie-Knowles et al., 2019) in which the authors explore wide-ranging aspects of 'the radical re-imagining (or de-imagining as they call it) of educational theory and practice ... in the shadow of the Anthropocene' (p. 276, 278).

Educational leadership has a crucial role in shaping the culture of schools and the praxis of Climate Change Education (CCE). Educational leaders must lead this transformation of education in the context of what Shields (2013) calls a VUCA world (a world dominated by volatility, uncertainty, complexity, and ambiguity). We argue that the climate emergency and the awakening of societal climate activism constitutes a context for school leadership that currently ranks somewhere between complex and chaotic on Gilbert's (2015) interpretation of the Cynefin leadership framework developed by Snowden and Boone (2007). Gilbert (2015), in her essay on leadership in collaborative complex education systems, argues that the climate emergency cannot just be a new input into an old system that 'will just be colonised to old ways of thinking' (p. 2) and that the required change has to come from 'within the system, not from top-down' (p. 9) and from the 'interactions between the system's elements - people (teachers, students, school leaders, parents, policymakers, researchers etc.)' (p. 9). Complex systems constitute a 'domain of emergence' (Snowden \& Boone, 2007) in which solutions emerge through experimentation that is safe to fail. Shields (2013), citing Caron (2009), argues for transformative leadership that emphasises 'not the volatility, uncertainty, complexity, and ambiguity that are givens, but the need for vision, understanding, clarity, and agility' with 'foresight, insight, and action' (p. 5). 
Assemblage theory, initially developed by Deleuze and Guattari $(1977,2004)$ and made more readily accessible by DeLanda $(2013,2016)$, is emerging as a useful tool to engage in a critical analysis of the complex relationships in social and educational contexts. Here, we are using assemblage theory in the thematic analysis of our research data and to derive suggestions for the direction school leadership could take to enable deeper engagement with CCE and the transformation of society towards sustainable futures. Due to the climate emergency, our future now hinges on understanding the complexities of the entanglement of society and culture with Earth system processes (Barad, 2007; O'Brien, 2016; Verlie, 2017, 2018). The dramatic climate change-induced events of 2021 remind us that Swyngedouw (2013) was likely correct and that 'the apocalypse is already here' (p. 17). However, Swyngedouw then reminds us not to despair but instead to focus on the 'emancipatory possibilities of apocalyptic life' (p. 17) and on driving the cultural transformation and the politicisation of the environment required to navigate dystopian futures.

\section{Background - curriculum and policies in the space of CCE leadership in Aotearoa New Zealand}

Educational leadership from the perspective of our research is positioned in the context of the national curriculum and the educational, cultural and political landscape of Aotearoa New Zealand. Aotearoa New Zealand has no formal constitution as a country but relies on the historic Treaty of Waitangi, Te Tiriti o Waitangi, signed in 1840 between the indigenous Mãori population and the colonial British Empire as its founding document and anchor for the bi-cultural status of the nation (Orange, 2021). Te Tiriti has profound implications for the nation's education system (Glynn, 2015) and will undoubtedly also be shaping the outlook for the national engagement with climate change and CCE.

The New Zealand Curriculum (NZC) (Ministry of Education, 2015) is the guiding document for education in Aotearoa. In its inception, the NZC echoed recommendations from the 1975 founding Environmental Education (EE) document, The Belgrade Charter (UNESCO, 1975). Its principles outlined the need for community engagement and future focus and offered values that supported the concept of ecological sustainability. The key elements of the NZC align well with EE and offer curriculum guidance to school leadership while allowing flexibility and autonomy within schools to reflect their individual character and community. Furthermore, the NZC suggests EE can be used as a conduit for students to become 'confident, connected and actively involved life-long learners' (Ministry of Education, 2015, p. 8). Overall, EE is well-fitted to the framework of the NZC. However, undermining this intent is the vague and voluntary nature of associated educational policies in regards to EE. For individual schools the level of engagement with EE depends largely on the school's elected governing arm, the school's Board of Trustees (Ministry of Education, 2015, p. 44), the school's leadership team, and often relies on poorly supported but motivated individual teachers within schools. It is, therefore, no surprise that climate strike youth leaders, interviewed at the University of Auckland Sustainable Development Goals workshop (Glasgow, 2019), decried the lack of leadership and governance support for EE/CCE at their schools. This lack of support has been documented globally (Kwauk, 2020). The studies reported here suggest that youth and teachers are aware of the incommensurate educational policies and practices in the face of climate change and are demanding educational transformation that will lead to genuine capacity building necessary to address climate change.

Kwauk (2020) analysed issues that hold back the education sector in the times of climate change and highlights hesitancy, lack of knowledge and vision, and structural limitations of school leadership as critical roadblocks. Kwauk (2020) argues that school leadership frequently has a polarising and ambiguous stance towards the treatment of climate change and often fails to take or encourage action by staff and students due to perceived constraints by policies and accountability (p. 7). Kwauk (2020) further states that the lack of leadership leads to a lack of support at micro and macro levels, from encouraging teacher education for sustainability to directing 
institutions towards implementing meaningful sustainability curricula and assessment. This lack of leadership translates into a failing demand for the resourcing and the building of capacity factors for climate education at all levels and promotes a 'lukewarm stance on climate action' by the school system (p. 8).

In the 1990s, the Aotearoa New Zealand school system underwent a market-oriented reform based on neoliberal ideology and committed to an agenda of globalisation (Codd, 2005; Gordon, 1992). These reforms, according to Codd, resulted in an 'erosion of trust and a degradation of teaching as a profession' (2005, p. 193) and the education system moved closer to the 'orbit of economic policy' (Codd, 2005, p. 193). The climate emergency is an anathema to neoliberal doctrines and the management culture these have evoked in education. Wilks, Turner, and Shipway (2019) argue that 'the dominance of neoliberal governance structures in school management' (p. 80) contributed to an increase in self-legitimising structures of regulation, compliance with 'myard of policies, procedures and processes' (p. 81), which resulted in a risk-averse and success-metric driven administrative style. Risk aversion, as Wilks et al. (2019) argue, has been amplified by complicit media and their reinforcement of neoliberal governance. It filters down to teachers and students and generates 'disembodied learning' (p. 83) and 'disempowered students' (p. 85). We argue that this neoliberal culture has set the scene for many of the difficulties of the education system to engage proactively with the cultural transformation required to maintain McNeil's 'dark optimism' (Cutter-Mackenzie-Knowles et al., 2019, p. 278) in the light of the unimaginable disruptions heralded by the climate emergency.

On a positive note, CCE and the cultural transformation this entails would not be the first significant transformative process for Aotearoa New Zealand's education system that distances itself from the neoliberal drift. A successful example was the Te Kōtahitanga programme for 'culturally responsive pedagogies designed to enhance Māori student achievement based on the Effective Teaching Profile concept' (Meyer, Penetito, Hynds, Savage \& Hindle, 2010, p. 2). The programme focused on cross-curricular intervention to improve Māori (indigenous people of Aotearoa New Zealand) academic achievement by reshaping mainstream schools. A considerable body of evidence confirmed Māori achievement improved at schools in the programme compared to those who were not (Ministry of Education, 2021). In order to achieve success for this transformative programme, Meyer et al. (2010) highlighted the need for 'school leadership to achieve whole-school change' (p. 2) and for 'a permanent senior teacher leadership role' (p. 6) assigned to this project. Bishop (2019) argued that for effective educational reform to occur, school leaders must support ongoing and collaborative transformational practice. Lessons learned from the implementation of the Te Kōtahitanga programme may be transferable to the cultural change that CCE mandates.

\section{Rationale and context of our studies}

During 2020 and 2021, we conducted qualitative research in two separate studies with climate activist teachers and climate strike student leaders in Aotearoa New Zealand to gather information about the lived experience of the research participants with respect to CCE at their respective schools. Our research coincided with the rise of the student strike movement that Greta Thunberg initiated (Murphy, 2021) and the selected episodes from our teacher and student interviews in this paper centre around the management of the situations surrounding the student climate strikes by the respective school leaderships. The climate strike movement motivated millions of youth worldwide and, as a result, begs deeper exploration into student engagement, agency and climate action (Bright \& Eames, 2020). It is acknowledged that this situation was unprecedented for school leadership teams and that the management of student participation during the strikes was problematic for many secondary schools. It forced school leadership to take a stand and thereby revealed some of the challenges that school leadership will face in confronting the climate emergency. 


\section{Methods}

The studies reported here were designed using a qualitative approach for data gathering and a postqualitative approach for the analysis of our findings in reference to assemblage theory. In the study with teachers, the recruitment of the participants was undertaken on teacher-centric social media sites in Aotearoa New Zealand. Seventeen participants self-selected or were selected by snowball sampling based on their self-declared stance as climate activist teachers into the study. Three of the participants worked in teacher education or in professional development, the remaining participants were high school teachers. The participants came from a mix of rural and urban schools. Two participants were Māori. The participants were initially interviewed using openended, unstructured interviews that permitted rich data on their experience to be obtained in a method inspired by the Pacifica tradition of the Talaloto (Naufahu, 2018). Subsequent data were gathered using structured surveys. In the study with climate strike leaders, fifteen student leaders from rural and urban schools were selected via social media and snowball sampling to conduct semi-structured interviews via zoom. The data from both studies were thematically analysed using Nvivo. The narratives of our participants were augmented through triangulation with knowledge gathered about the respective schools through the schools' public websites, the researchers' knowledge of the educational landscape in Aotearoa, as well as geographic and publicly available demographic knowledge about the location and the communities of the respective schools. Ethics approval for the respective studies was gained from the University of Waikato and informed consent was sought from all participants, including from parents of the students who participated in the study. Confidentiality and anonymity were enhanced through the use of pseudonyms and the disguise of localities.

\section{Assemblage theory as an analytical tool}

Inspired by St. Pierre (2018) to apply postqualitative elements in the analysis and the discussion of our findings, we refer to the posthuman relational ontology and the theory of assemblages. Assemblage theory, based on the work of Deleuze and Guattari (1977, 2004; see also Deleuze, 1988), and later developed by DeLanda $(2006,2013,2016)$, has been increasingly referenced as a methodology for critical research (Baker \& McGuirk, 2017; Fox \& Alldred, 2015, 2016; Bazzul \& Kayumova, 2016). In our application of assemblage theory we cite DeLanda (2016) frequently due to the excellent summary DeLanda provides of the extensive writings by Deleuze and Guattari, who developed the key elements of assemblage theory. We refer to DeLanda (2016) for references to the original works by those authors. Assemblage theory conceptualises reality as a material-discursive manifold of potentialities that is morphogenetic for and shaped by heterogeneous and material-discursive assemblages of humans and more-than-human entities in which humans and the environment are combined in a flat ontology and relationality is highlighted over essentialism (Fox \& Alldred, 2020, p. 270). Delanda (2016) depicts the Deleuzian agencements [assemblages] as bricolages of heterogeneous elements, most of which are assemblages in themselves. The word 'assemblage', suggestive of a passive and constructed composition, is a problematic translation of Deleuze's French term 'agencement', which evokes a sense of autonomy, agency and dynamism.

Assemblages delineate the belonging of their components through territorialisation and enforce internal cohesion and function through coding. Referring to the work of Deleuze and Guattari, DeLanda (2016) introduces the concept of these two parameters being like 'knobs' (p. 3) which can be set to different values (Figure 2).

Territorialisation, according to DeLanda (2016) refers 'not only to the determination of the spatial boundaries of a whole - as in the territory of a community, city, or nation-state but also to the degree to which an assemblage's component parts are drawn from a homogeneous repertoire, or the degree to which an assemblage homogenises its own components' (p. 22). 


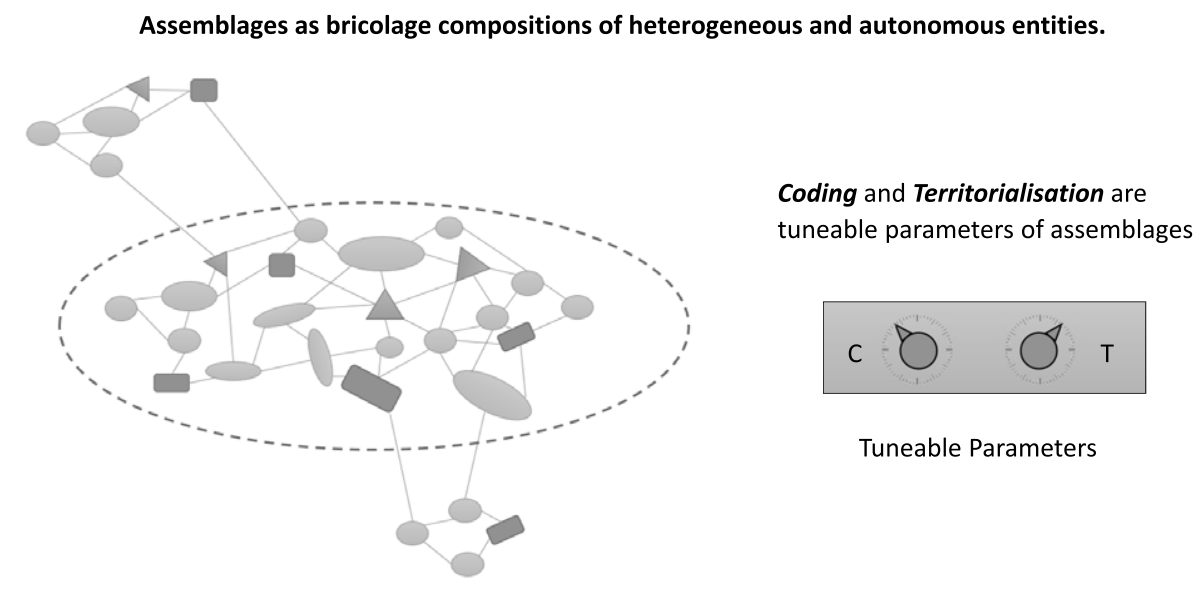

Figure 2. Assemblages, according to DeLanda (2016) are bricolage compositions of heterogeneous and autonomous entities. Coding and Territorialisation are understood as tuneable parameters of the assemblage.

Territorialisation is a measure of distinction and belonging and a delineation between 'us' and 'them', between who or what is inside or outside of the assemblage. A reduction in the territorialisation parameter of an assemblage is referred to as deterritorialisation. The term deterritorialisation is also applied to a process that takes a subject out of a territory and results in a loss of belonging or association with an assemblage. Deterritorialisation of a subject results often in a reterritorialisation into a different assemblage or territory. In the human domain, climate change could lead to a process of significant and literal deterritorialisation for affected communities with a likelihood of dystopian proportions of future climate refugees. And in this paper, we will argue for the need to deterritorialise the assemblages of education, a sentiment that is reflected by CutterMackenzie-Knowles et al. (2019).

Coding of the assemblage, according to DeLanda (2016), refers to 'the role played by special expressive components in an assemblage in fixing the identity of a whole' (p. 22). The expressive components can be emerging phenomena such as the genetic coding of DNA in living cells, or intrinsic physical laws, or, can be deliberately generated in the case of human control within assemblages. Coding supports the legitimacy of the authority structure within the assemblage through 'linguistically coded rituals and regulations' (p. 22) such as written or spoken rules and procedures and lays out the rights and obligations of the assemblage's components. The more authoritarian an assemblage becomes, the more explicit and wide-reaching its coding gets, limiting the degrees of freedom of the components. The discussion by Wilks et al. (2019) of the neoliberal coding of the assemblages within the education system is an example of coding in the context of our research.

Schools are an example of assemblages (Figure 3). According to assemblage theory, assemblages are evoked and move within a manifold of potentialities (Delanda, 2016, p. 119). This manifold is a combination of the physical and social space. Assemblages reposition themselves in this social-material manifold in a search for optimising certain parameters of their output. Traditionally schools strive to excel in their prime function of successful social reproduction and promotion of important cultural traits. Climate change and the resulting climate emergency as events are reshaping the social-material manifold of potentialities with far-reaching consequences. The productive processes of morphogenesis within this social-material manifold are fundamentally affected by this reshaping, with implications for the assemblages that constitute themselves within this space (Figure 4). The assemblages of schools and the assemblages of school leadership are under particular pressures to respond. 


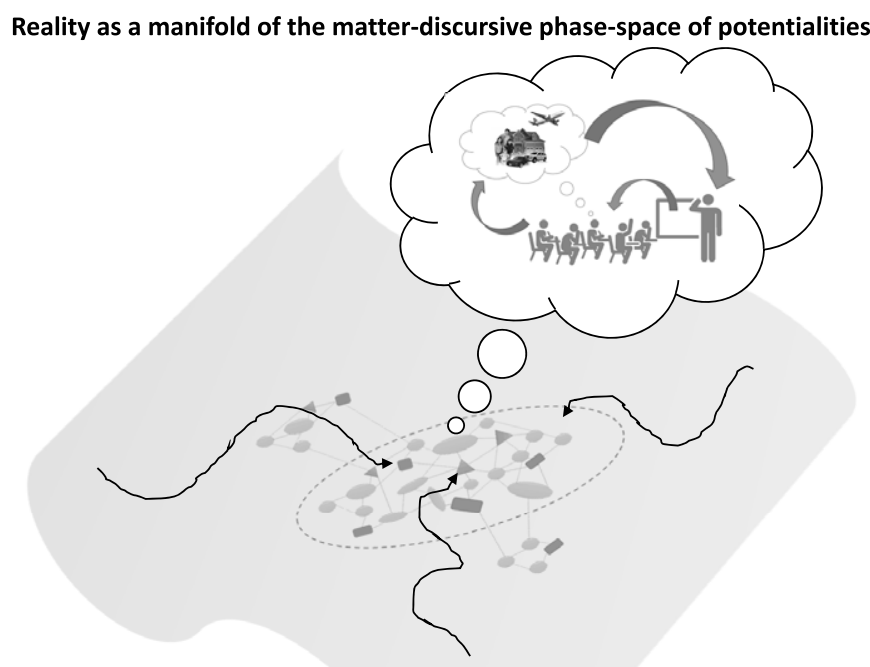

Figure 3. Schools are culturally reproductive assemblages within Delanda's manifold of potentialities.

\section{Climate change re-shapes the manifold of potentialities}

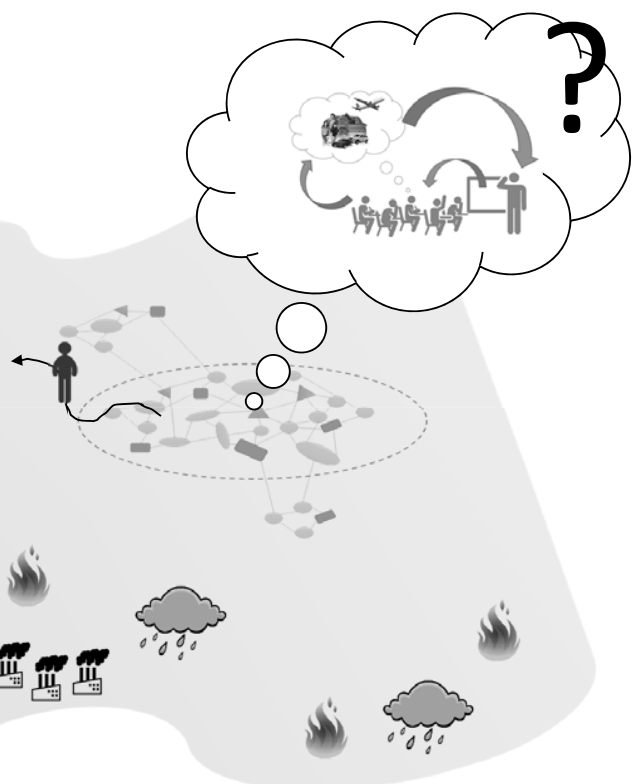

Figure 4. Climate change is a matter-discursive process that reshapes the manifold. Culturally reproductive schools are no longer optimal. Climate change aware individuals seek to actualise new possibilities along lines of flight. Cultural reproduction becomes questionable. 


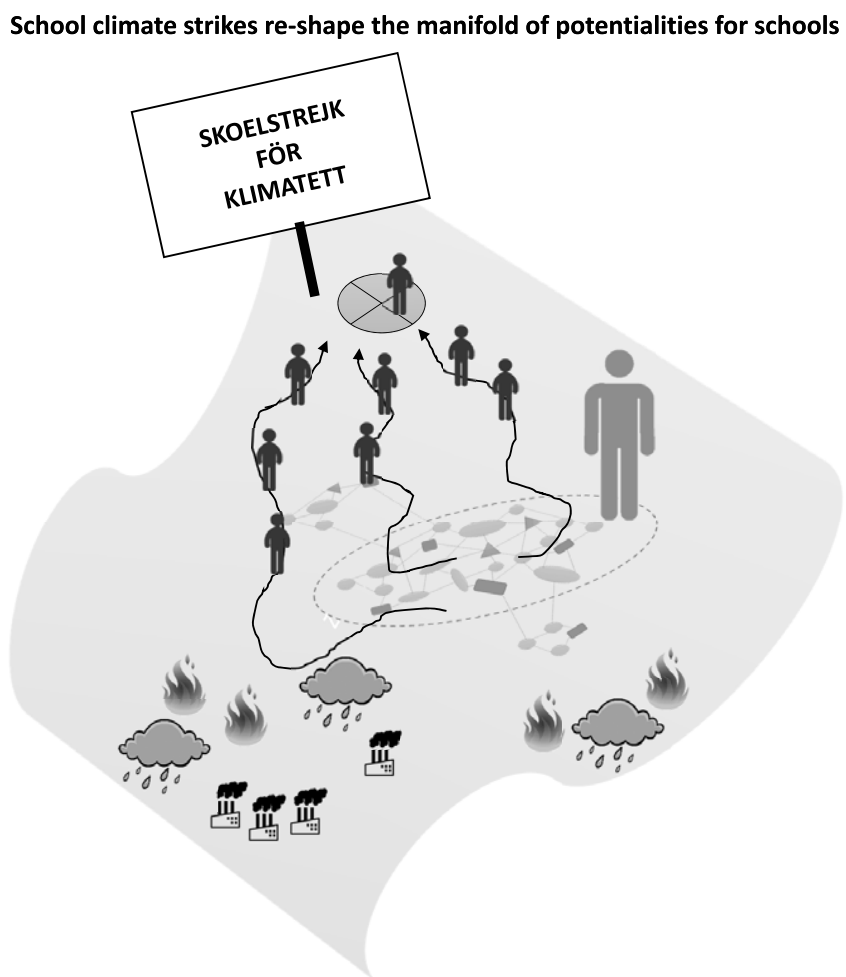

Figure 5. The school strike youth movement transforms the manifold of potentialities further, challenging the territorialised and coded assemblages of schools. Climate activist students and teachers act as bellwethers and informants. Lines of flight lead to new attractors and re-territorialisation in new assemblages.

The climate strike youth movement added a new dimension to the reality in which the assemblages of schools exist (Figure 5). Education has fundamental obligations due to its capacity to affect the social dynamics that will determine our future. How education responds to this challenge will be crucial. The application of assemblage theory as an analysis tool for climate change policy development by Fox and Alldred (2020) was inspirational to our approach. We here apply assemblage theory as a methodological and analytical framework for analysing schools and school leadership as assemblages. We also conceptualise the situation of teachers and students as assemblages and consider how the dynamism of the climate emergency and the reactions of school leadership generate manifestations of deterritorialisation and re-territorialisation for the affected individuals (Fox \& Alldred, 2015, p. 401). Fox and Alldred (2015) state that 'power resides in the affective flows between relations in assemblages' (p. 402), and research itself must be understood as a territorialising assemblage that 'shapes the knowledge it produces according to the particular flows of affect produced by its methodology and methods' (p. 403). It is here noted how the verb 'affect' is at times used as a noun in new materialist literature when contextualising a process of affecting as a phenomenon and a subject in its own right.

\section{Findings and Discussion}

We found that the experiences reported by students and teachers were primarily determined by the schools' leadership stance on the climate emergency. Through the lens of assemblage theory, DeLanda's (2016) territorialisation and coding parameters, patterns emerged from our data. 


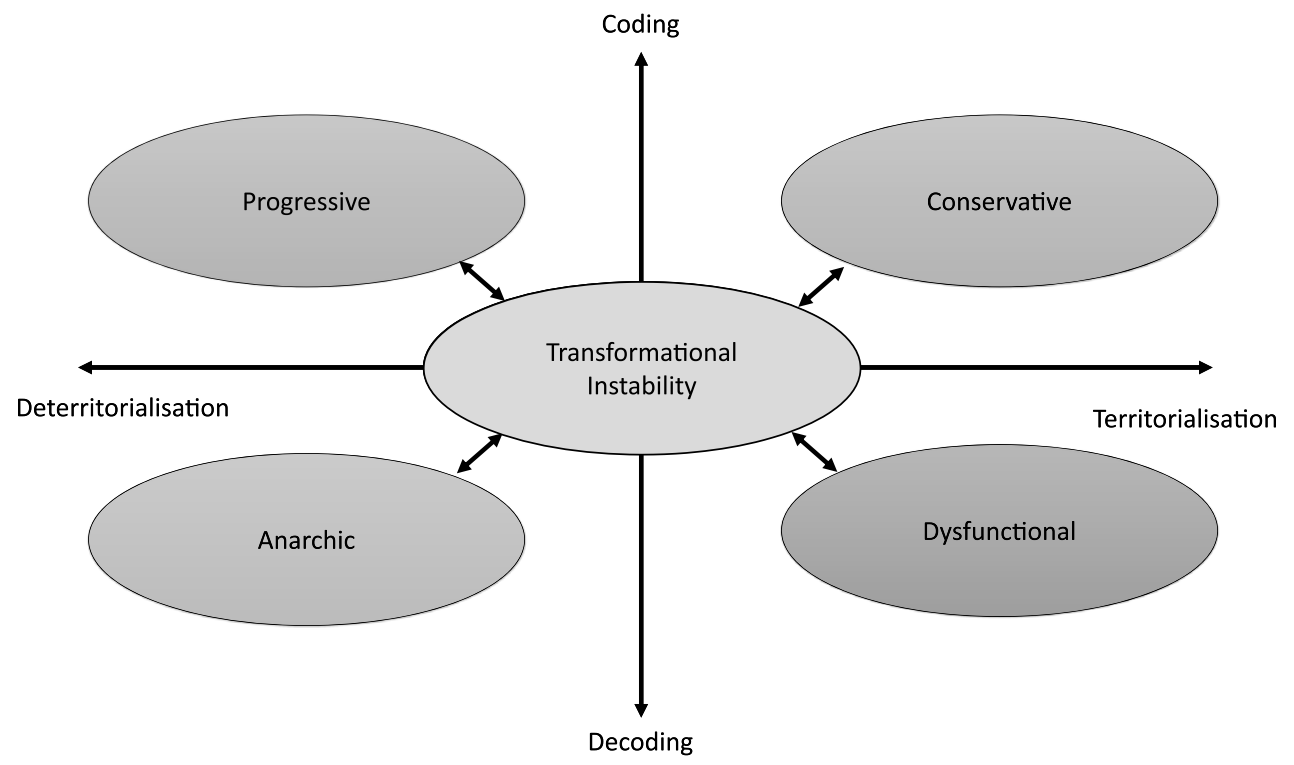

Figure 6. Coding and territorialisation continuum (CTC) of assemblage governance.

We, therefore, have structured our findings in thematic groups depending on where we could place the assemblages of their respective schools on a coding versus territorialisation continuum (CTC) (Figure 6).

We labelled the positions of assemblages in the four quadrants on the CTC as conservative, progressive, anarchic and dysfunctional. High levels of coding correlate with disciplined and well-organised structures. High levels of territorialisation correlate with closed, dogmatic, defensive and conservative structures. The conservative position is characterised by well defined and defended territory and a strict set of coding. Traditional grammar schools within the context of education in New Zealand befit this label. Progressive schools explore new territory but often within a well defined and codified accountability structure. In the anarchic space, a lack of coding and territorialisation maximises freedom. The anarchic space is also a creative space but a lack of structure can inhibit the effectiveness and reach of its impact. With high levels of territorialisation demands and defensiveness but a lack of functional coded structures in support, the lower right quadrant on the CT continuum signals a dysfunctional assemblage.

Internal structures within schools often reflected their outward stance. The territorialisation of internal structures into faculties emerged as a point of critique by students and teachers in our research and was seen as a hindrance to the development of effective CCE. We labelled the centre of the diagram as transformational instability. We argue that this is a place of potential for change, a saddle of sorts, from which a descent into more stable positions on the CTC can follow. We argue that transformational instability is a position in which constructive creativity can optimise opportunities for the emergence of solutions. Most school structures we found from our research fall either into the conservative or the progressive domain on the CTC.

\section{Cases from conservative schools}

Karl is a science teacher at a private urban high school in an affluent community. Karl's experience is typical for teachers working in schools managed by highly territorialising and strongly coding management styles. Karl believes that the climate emergency is humanity's number one problem by a 'long shot'. He stated, 'If the Earth becomes uninhabitable by humans, nothing else matters'. 
However, his belief is not reflected in the stance of Karl's school management. Karl says that 'in terms of support from management, I've always tried to be a voice for solutions to climate change. But there's a huge amount of resistance to that'. Karl tried to organise students to participate in a school climate strike event. But Karl says, 'I was told, in no uncertain terms, that I was not to advertise that that was taking place on any public forum that the parents might hear about. I was told very specifically, no way, are you to tell the kids that this is happening, or to advertise their involvement'. They should be in school, was the answer. And Karl added, 'To hear that, you know, as a school, which prides itself on preparing kids for the future, I was really disappointed by that response from the management'. In order to address the climate emergency, Karl states 'We actually need to stop nibbling at the edges because that's just not going to cut it anymore. We need significant major, systemic, international, radical change to actually address these problems'. Karl highlighted the need for CCE. 'I don't think there's enough education taking place to let people know that actually, there are some really specific things we could do that would make significant differences'. Karl also highlighted the fact that climate change is not officially in the curriculum very much and that talking about climate change puts him 'off-topic' in his classes.

Karl's experience typifies many of the experiences reported by our other participants from conservative schools. His school's leadership remains entangled deeply in the power structures that define the conservative and culturally reproductive habits of their school. The assemblage in which his school leadership operates, according to the analysis of Karl's narrative, appears to be dominated by the following relations (in no particular order):

\section{parental concerns; parental cash flow; school status; student achievement and excellence; pres-} tige; discipline; order; economics

From the perspective of the school management, the environmental materialities of climate change are absent in this assemblage, which appears to be constituted solely from the conservative sociocultural elements in which the school operates. The leadership constitutes their stance through transactions of power relationships between the parents who send their students to the school and pay tuition fees, the pressures of maintaining discipline, an apparent disdain for real student agency, the maximising of subject learning and credit gathering for the sake of excellence in the culturally reproductive domain in which the school operates. We argue that Karl's story is an example of a category mismatch of leadership reaction. The leadership in Karl's school reacted in what they may have thought of as best practice, regarding the context of the climate emergency as a simple context and perhaps a mere disturbance (Snowden \& Boone, 2007, p. 2). Their management style had been successful in the neoliberal growth economy that defined their task as ensuring the seamless and trouble-free reproduction of students and their achievements in the image of their parents. The significance of the change in the context that the climate emergency constitutes has been missed. As Snowden and Boone (2007) state, this can lead to 'catastrophic failure' (p. 3). Karl's school leadership increased coding by making explicit directives to not talk about the climate strikes and it increased territorialisation by enforcing students to remain in the school territory, physically and conceptually. The school's territorial borders became less permeable (Figure 7).

Karl chose to abide by the management directives but reported a significant amount of frustration, anger and alienation. Karl has deeply understood the gravity of the situation humanity finds itself in yet has found himself 'stripped of power' (Jones \& Davison, 2021, p. 194) by the way his school leadership operates. The cognitive dissonance between what Karl knows about climate change and being forced to comply with the restrictive stance of his school leadership appeared to be painful for Karl, with all the negative consequences for his well-being that this entails. Karl accepted this disempowerment, and he, in turn, through his compliance, disempowered his students in a typical cascade of hierarchical power relationship entanglements that begin with the school leadership. Analysing Karl's options, he could have resigned from his job or at 


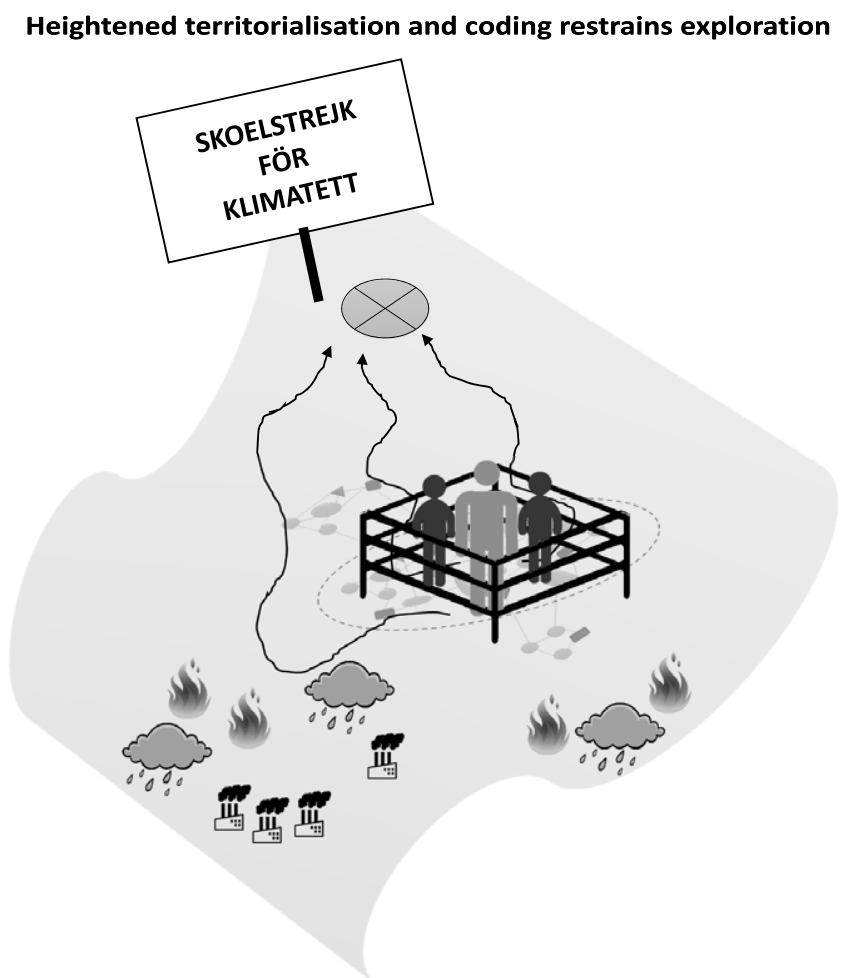

Figure 7. Karl's school reacted by increasing territorialisation and coding, attempting to block lines of flight.

least offered his resignation unless management permits him and his students to engage in the CCE space in the way he saw fit. But wider societal power structures made such a move unlikely. Karl is embedded and constrained by the entanglements of his own life and the many, often conflicting, obligations that surround them. He has a family to support and perhaps a mortgage to pay. But central to Karl's professional frustration is the stance of his school leadership. Karl's assemblage in no particular order differs significantly from that of his employer.

climate emergency; science knowledge; deep concerns about the future; family; economic constraints; school culture; school leadership; colleagues; climate denial in society;

Karl's dilemma is reflected in choices made by some teachers in the UK, who gave up their teaching jobs to fight the climate crisis (Staufenberg, 2019). The actions of the leadership of Karl's school caused a deterritorialisation of Karl with respect to his role at the school and a re-territorialisation within the event of the research assemblage where he was given the time to speak about his concerns freely. Karl was set on a line of flight away from the assemblage of his institution. This is a line of flight for Karl but not a line of exploration for Karl's school. It takes Karl away from the school and distances him from his potential within the school to generate a CCE initiative within the school.

The assemblages of the climate strikes were confronting for conservative schools' leaderships. Seven out of 15 strike leaders interviewed in our research experienced school leadership that actively discouraged or attempted to deter student participation. Flora and Josh's experiences typify the narratives of those from unsupportive secondary schools, reflecting the relationships of power and politics on both student agency and educational outcomes. Flora attended a large city 
school, and at 15 years old, she was environmentally aware and wanted to strike. However, 'they would punish us, even if your parents sent a permission letter. Their usual policy was one detention per period missed', she said. Josh lived in a rural community that drew students from a predominantly farming community. His school's reluctance to support the strikes was possibly due to negative perceptions held within the community concerning the link between agriculture and climate emissions. He said, 'I put up a few posters but I was promptly called into the Principal's office, being one of the only environmental students, and he told me to stop and I wasn't allowed to use the school to advertise'. Both felt their climate action isolated them from their school, ironically restricting the opportunity for them to be connected, confident and actively involved, a vision promoted in the NZC (Ministry of Education, 2015). The irony, that despite the curriculum's vision some adults attempted to define and regulate the type of agency and involvement occurring (Gordon, 2010), was apparent to many strike leaders. For many students, the strike leaders believed, the lack of school support scuttled their motivation and agency, but for Flora and Josh, their determination to raise climate awareness and enable youth voice emboldened them to defy traditional authoritarian expectations.

Paradoxically, the assertion of power shown by leadership in unsupportive schools had the potential to undermine the respect students may previously have held for the system. Lajos described learning 'a lot about power' from his strike experience, saying 'teachers or any authority making a threat of expelling or whatever, we learned, that is only possible so long as it is easier for them to do it rather than not do it'. Lajos' ethical stance, he considered, was justified by the urgency of the climate crisis and the size of the movement that, for many students, was more compelling than traditional school structures and expectations. The strike leaders perceived the need for cultural transformation to overcome the industrial cultural reproduction mode of traditional education.

The leadership assemblage of the conservative schools reported here did not include the climate emergency, climate change, and the material world. Instead, it relegated them to a disturbing context that is extrinsic to the business of the school. The disciplinary actions of the leadership deterritorialised the students and re-territorialised them into new assemblages of their own choosing, in which the power relationships of the school leadership and their ability to affect was no longer effective. For Flora, Josh and Lajos, significant learning happened outside the school context in a self-organised manner. Their respective school's leadership assemblage appeared limited to classical points relevant to socially reproductive schools. In no particular order:

parental concerns; discipline; hierarchical order; school status; student achievement; risk management; timetable; routine; consistency;

For the students themselves, a very different assemblage emerged. In no particular order:

climate emergency; social justice; deep concerns about their own future; climate denial in society; friendships with other activists; actions; lines of flight from school;

\section{Cases from progressive schools}

There were also notable cases where school leadership engaged proactively with CCE and has been welcoming and supportive of teacher and student engagement in climate activism and leadership. Tanya's experience is one such example. Tanya teaches social science at a progressive suburban public high school. She wanted to support the students in her class in the climate strikes. She sought permission from her school leadership and asked if she could organise a bus. Tanya wanted the students to be marked truant in order for them to feel and discuss their rebel experience with their parents. She reported that the principal said, 'No, they can't be marked truant. But I agree with you. It's valuable learning. I understand that you want them to feel like rebels, but we're going 
to mark them as on a school trip'. The school hired a bus to take Tanya's students to the climate strike. When more students wanted to join the trip, Tanya's principal was very supportive. Tanya reported, 'So we're back to the principal. I mean, what if other students want to come and she was like, the more, the merrier. So we booked another couple of buses'. Besides the support Tanya received from her school leadership in the climate strike events, she was also able to start senior courses for students in social anthropology, focusing on citizen activism and how this can generate significant transformations in society. Tanya's school leadership appeared to realise the fundamental shift in paradigms that the climate emergency constitutes and is creating the space and capacity for teachers and students to engage constructively towards emerging futures through the engagement at the school. The assemblage of the leadership situation with regards to the climate strikes at Tanya's school includes more-than-human material affects. In no particular order:

atmosphere; greenhouse gasses; emissions; climate emergency; students' concerns about their future; students' agency; action learning; busses; teacher autonomy; high trust relationship with staff; trust relationship with students; strike as valid action; citizen activism as a valuable learnable skill

The leadership at Tanya's school managed the climate strikes and engagement with social transformation in a way that supported staff and student agency and permitted 'collective intelligence' (Gilbert, 2015, p. 11) to emerge. Tanya reported on the significant learning experience her students had at the climate strikes, the social interactions between the students and the public and the emotional engagement of the students in the experience of the strikes. Tanya, the students, her colleagues, and the school's leadership effectively collectivised (Nairn, 2019) their concerns about the climate emergency and the students' actions in cooperation with the teachers and the leadership generated hope. Tanya's narrative throughout our interview conveyed satisfaction with her employment and a sense of achievement towards transformational learning at her school. The school leadership as an assemblage encompassed the climate emergency and, in doing so, established a territory in which both students and teachers were included in their climate change concerns, constructive actions and inspired learning.

Tanya's school leadership reduced the degree of territorialisation and coding at the school in order to extend the realm of learning well beyond the school fence and into society (Figure 8). It embraced the challenges as learning opportunities and the teachers' and students' actions as potential lines of exploration that can bring back new knowledge and enrich the school's culture, instead of pushing teachers and students out of the school along lines of flight (Bazzul \& Kayumova, 2016, p. 288).

Students like Marama and Madison, who attended progressive schools that were supportive of the climate strikes, reported experiencing an emerging cultural r/evolution that included the schools themselves. As a result, they reported feeling a greater sense of empowerment and agency within their schools. The strike leaders applauded the leadership of schools who dared to endorse them, stating some schools 'were outstanding' with their support. Marama recalled, 'my school was actually very pro-strike, most of our school was going anyway. I went to the first strike and it was the most life-changing experience and most empowering feeling to be there with everyone else'. The collective response-ability Marama reported characterised the strike leaders' experiences as both empowering and heightening political awareness. A political awakening was considered imperative for effective climate action. 'I had never been involved in anything political before', said Madison, 'it widened my understanding that politics affects everything, to be an advocate and if you want change, you have to be political'. From the students perspective the leaderships of supportive and progressive schools appeared to have the climate emergency and the implications this entails included in their assemblages. In no specific order: 


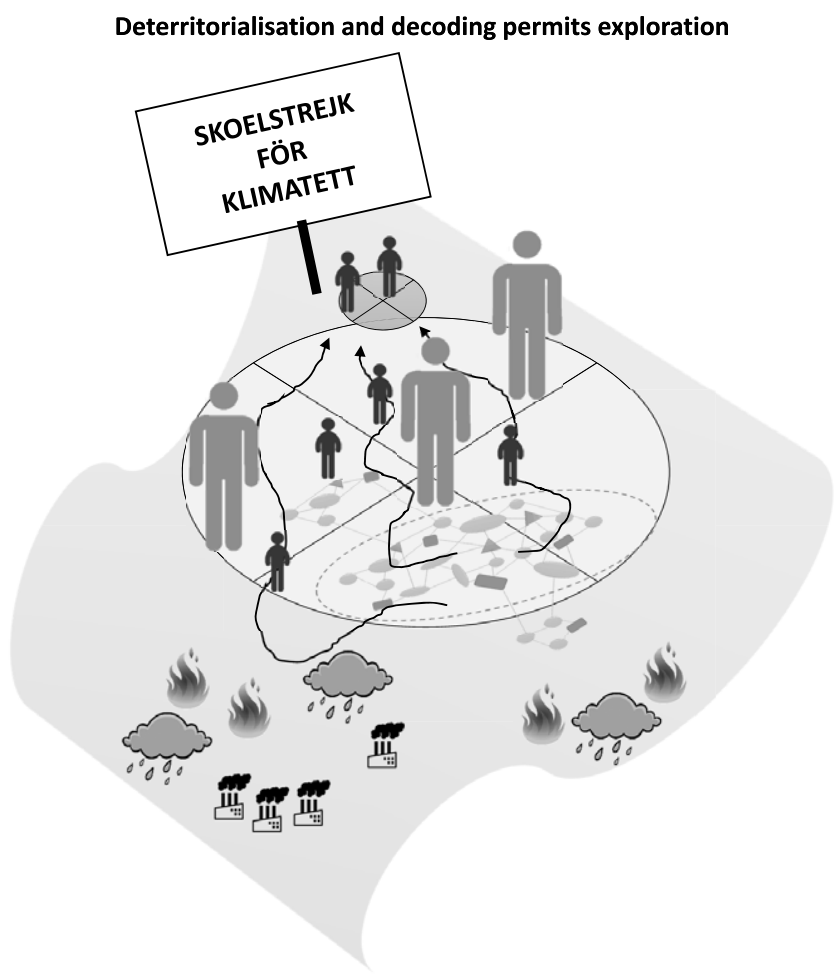

Figure 8. Tanya's school turned lines of flight into lines of exploration through deterritorialisation and decoding. The assemblage of the school is steered towards new possibilities.

greenhouse gasses; emissions; climate emergency; students' concerns about their future; students' agency; action learning; teacher autonomy; trust relationship with staff; trust relationship with students; strike as valid action; citizen activism as a valuable learnable skill; political skill-building in students; social justice; intergenerational justice;

\section{Schools as transformative spaces}

As the climate crisis necessitates transformative processes, the territorialisation and coding within schools must also transform. The evidence from our research suggests that effective CCE would benefit from a new style of educational leadership that permits experimentation, student and teacher agency and community engagement to promote the transformation of society towards a sustainable future. Leadership that fostered a culture in which teachers were encouraged to engage with CCE and students were empowered to embrace student activism generated the potential to develop 'collective intelligence' (Gilbert, 2015, p. 11) in a complex realm. This leadership style effectively applied a deterritorialisation and decoding strategy that allowed students and teachers to emerge from the traditional school setting into a realm of exploration and experimentation. This experience contrasts with schools in which the leadership was antagonistic towards climate change and CCE, enacted disciplinary measures to prevent students from attending climate strikes, and even directed teachers to suppress any discussion of student climate activism. These leaders suppressed the synergy of the domain of emergence (Snowden \& Boone, 2007) to the detriment of outcomes by amplifying and enforcing territorialisation and coding in the attempt to preserve order and hierarchy and in denial of the reshaping socio-material reality around them. 
The call for deterritorialisation and decoding of school leadership also applies to the faculty structure of schools. The climate emergency is a multi-faceted problem affecting all areas of learning and, as Bright and Eames (2020) argue, would benefit from cross-curricular approaches. Kwauk (2020) also identified the current lack of cross-sectoral coalitions in the education system as one of the roadblocks to effective CCE (p. 20), and Stevenson, Nicholls, and Whitehouse (2017) argue that cross-curricular approaches could give CCE the necessary space (p. 70). However, the traditional territorialised faculty and middle management structure of schools as well as firmly defended territories on timetables and within course structures are a significant hindrance. The voices from the climate activist teachers and students in our study confirmed this, with many participants citing the need for more cross-curricular engagement and the lack of space on packed timetables as priority concerns. Depictions of assemblages of departments within schools reveal a frequent lack of space for holistic thinking and a focus on traditional best practices, administrative workloads and a lack of capacity for cross-disciplinary collaboration. Paulene teaches at an urban public high school. She said, 'Our school is still very siloed in terms of the curriculum'. But Paulene is 'trying to find ways to sneak climate change into lessons and into every course I teach in one way or another'. Jessica also teaches at an urban public high school. She frames cross-curricular work towards generating CCE learning in terms of infiltration of ideas into multiple other contexts. 'So, I infiltrate everything I teach, really, with the environment. I reflect that actually, just gentle infiltration is really important as well. So, a little bit of titbits here and there, and every little bit counts'. Jessica's strategy of 'gentle infiltration' and Paulene's way of 'sneaking climate change into lessons' are examples of deterritorialising lines of flight, exploration and morphogenetic activism that shifts the assemblages in schools from within. Leadership that would grasp the importance of accelerating these shifts could turn the gentle infiltration into a school-wide overt strategy by proactively deterritorialising departments and faculties.

Some schools, however, already made deliberate attempts to generate collaborative learning teams, with members from different faculties cooperating towards co-created courses. Our research participants working in such schools cited the holistic cross-curricular learning opportunities their schools enabled as an important factor in work satisfaction and the generation of hope. Moana teaches middle school years at a public high school where the old faculty structure is dissolved, and curriculum areas are combined. Moana's school has a large component of urban Māori students, and Te Ao Māori, the holistic worldview of Aotearoa's indigenous people, is an integral part of the school's culture. Moana states: 'And basically, the program's integrated, so there's no English, Maths class. It's all sort of project-based inquiry learning'. In Moana's school, about three staff members are allocated to 50 learners, and specialist teachers come in to support the integrated learning programme. Moana says 'I really enjoy the transdisciplinary learning. So you know, incorporating, so for example, in my course, sustainability standards, and mātauranga standards, with Te Ao Māori as being the hook. Yeah!' Moana says she feels very grateful to be where she is and emphasises her ability to deliver 'firstly, the mātauranga Māori [knowledge, wisdom] around climate change'. The assemblages of Moana's school and herself which emerged from our data seem congruent, contributing to the vibrant positivity that radiated through Mona's interview and her hopeful perspective towards making a positive contribution to her students' developing world views in the light of the challenges we face. This is likely also a testament to the quality of leadership at her school. Moana and her school connect multiple systems of knowledge into a holistic and caring assemblage. In no particular order:

Te Ao Māori; Mātauranga Māori; Western science and mathematics; climate; students' concerns about their future; students' agency; action learning; teacher autonomy; high trust relationship with staff; trust relationship with students; holistic care; Te Reo; place-based learning; land, water, air; teamwork; 
Many of the student strike leaders interviewed for this research expressed general concern over the historical failings of our Western neoliberalist culture and the way it has shaped education. For example, 13-year-old Lilly said, 'I was really confused why no one had done what was needed to be done, why they prioritised the economy over our future when there will be no economy if we don't have a future because you can't eat money'. This comment exemplifies the sentiments of the climate strikers who, notwithstanding their youth, innately understood the need for societal transformation.

The climate strikes of 2019 forced the assemblages of schools and their leaderships to react and revealed cultural divides within the educational landscape of Aotearoa New Zealand. The student strikes represented the concerns youth feel for their future, called for leaders to be accountable and demanded action. For decades youth have been active and notable catalysts for change. For example, the American civil rights movement, the American Vietnam war protests, the Chinese Tiananmen Square pro-democracy protest, the Arab Spring democracy movement in the Middle East, the American indigenous water rights protest (Blakemore, 2018), and more recently, the Hong Kong protest and climate strikes. The thinking that leads to youth activism is often alternative to or decades ahead of adults' perspectives. Because of their age, however, their voice is often dismissed (Barret, 2018). The assemblages in which many young people constitute their own persona benefit from being still unburdened by the power of economic and family responsibilities. Their assemblages demonstrate agility and readiness to accept and respond to risks. Schools could significantly benefit in developing constructive educational capacity by including, not excluding, student climate activism.

The NZC mandates a future-focussed formal education programme and, within sustainability, acknowledges the intergenerational injustice climate change posits for youth. In 2013, Robyn Boswell, the National Director of Future Problem Solving within the Ministry of Education, advised imagining the future with 'hope not horror' (Ministry of Education, 2013). From the perspective of climate strike leaders, the climate emergency constitutes a multi-dimensional paradigm shift. For the societal transformations essential to them to have 'hope, not horror' demands a reorientation of school leadership. Nearly a decade on, minimal progress appears to have been achieved to actualise hope. The call for transforming educational practice and pedagogy among the student strike leaders was a recurring theme. Strike leader, 18-year-old Marama, stated, 'their idea of education is so outdated, it needs a revamp, to be honest. There are so many kids that sit in class every day and are so unhappy with how the world is'. For many of today's youth, Boswell's 'future of horror', is here.

The need for transformative change dovetails with the voices for greater recognition of mātauranga Māori, the knowledge and wisdom of Aotearoa's indigenous population. In Aotearoa New Zealand, and with consideration of the Treaty of Waitangi (Orange, 2021), the opportunities for developing new ways of teaching and learning are particularly interesting with respect to the ongoing deterritorialisation and decoding of cultural and colonial territorial barriers and the creation of a productive partnership between Western and mātauranga Māori knowledge systems. Indigenous and local knowledge systems have been identified as crucial for safeguarding our common future against the oppression by the unsustainable practices of the neo-capitalist Western colonial hegemony (Fernández-Llamazares et al., 2021). It would go beyond the scope of this paper to attempt to give justice to this essential aspect of our country's grappling with our colonial past and with developing pathways to a sustainable future in a bi-cultural partnership. However, applying the ideas of Delanda's $(2013,2016)$ material-discursive manifold and assemblage theory to the discourse on local and global multicultural futures would seem like a natural progression from here with a productive environment for research within Aotearoa (Ministry for the Environment, 2007; Talwar, 2021; Tunks, 1997).

From the perspectives of DeLanda's $(2013,2016)$ assemblage theory, school leadership should aim to deterritorialise and decode the management of their schools in order to embrace the climate emergency as a normative and upending symptom for a rapidly changing world in which 
schools operate. Assumptions about the role of schools as cultural reproduction systems are no longer valid. As identified by both teachers and students, the climate crisis challenges the dominant culture itself to undergo significant systemic changes. The notions of deterritorialisation and decoding of the leadership assemblage in the face of the complex situation that the climate emergency constitutes are mirrored in Boylan's (2016) call for teachers to lead from below, in Gilbert's (2015) focus on the emergence of solutions from the interactions within the system, Snowden and Boone's (2007) leadership advice for complex and chaotic situations based on their Cynefin framework, and Verlie's (2018) call for a new and diffractive pedagogy.

DeLanda's (2013) understanding of assemblages as being constituted within and shaping the material-discursive manifold of potentialities brings human and material agency onto the same ontological playing field, a complex dynamic and morphogenetic space of social and material agency. Delanda (2013) argues that lines of flight describe movements of assemblages, such as individuals or schools, or the assemblage of a school's leadership, as 'relative accelerations' (p. 94) out of rigid morphologies. In times of complex crises, where solutions need to emerge with urgency, deterritorialisation and decoding encourage these accelerations. We argue that lines of flight can then become the lines of exploration that we need to walk with abandon. DeLanda's manifold of potentialities is a manifold of possibilities, resonances and synergies, and openminded and attentive exploration of this space can accelerate the finding of solutions. Rigid and territorialised morphologies, however, constrain this process and retain the assemblages and their components in a state of incapacity for evolutionary progress. Rigid morphologies, such as those experienced by schools reluctant to engage in the climate strikes, tend to devalue individuality and lead to the entrenchment of authoritarian and defensive structures.

The material reality of the climate emergency decentralises the human from the agential dynamics of the world, and society and education are finding themselves entangled-with and acting-with climate (Verlie, 2017, 2018). The complexities of the social domain become diffracted by the complexities of humanity's explosive expansion of the last century, its impact on the Earth systems and the consequential material dynamics of climate change that it unleashed. This diffraction (Haraway, 2018; Barad, 2007) reaches deeply into the structures and practices of our education systems and, as Verlie (2018) states, is therefore generative, enabling new, novel, innovative, creative or different phenomena to emerge' (p. 7). Verlie (2018) suggests a new diffractive pedagogy that 'cultivates creativity, reconfigures bodies and subjectivities, is dynamic, nonlinear, transdisciplinary, multi-modal, disruptive, unchartered, transcorporeal, interwoven, and one that troubles established categories' (p. 8). Verlie's pedagogy, in turn, suggests a diffractive style of educational leadership that fosters collective response-ability in which new learning and knowledge emerges from the intra-actions of students, teachers, community and the material world. We argue that the deterritorialisation and decoding of schools, their leadership and their internal structures can promote this emergence.

\section{Conclusion}

The climate emergency demands that schools and school leaderships interrogate what schools should now actually be doing. The traditional role of schools as institutions that guarantee the reproduction of culture is put into question, just as the role of the current neo-capitalist culture comes into focus as a fundamental contributing cause of the climate emergency and as the producer of the harmful environmental practices that got us into this trouble. While we believe that engagement with CCE should be mandated for all levels of the education system, we argue with Gilbert (2015) not for top-down regulation of CCE but for an approach to leadership that generates the space, encouragement and support for transformational interactions and learning to emerge by inspiring teachers and students to take ownership of this process. This will enable CCE to capitalise on the emergence of solutions through the collective creativity of the people 
within the system. Schools and their leaderships are now in need of redefining how they operate in order to transcend cultural reproduction towards active cultural transformation and a posthumanist culture that recognises itself, as Fox and Alldred (2020) state, as an 'assemblage of biological, sociocultural, and environmental elements, whose capacities to affect and be affected are contingent upon setting and its relations with other matter' (p. 272). This transition of schools into the reality of the climate emergency will require bold leadership and we argue that deliberate deterritorialising and decoding actions by school leaderships can promote this process. Teaching the existential threat of the climate crisis is an ethical imperative (Kessel, 2020). The stakes are as high they get.

Acknowledgements. We acknowledge the support for our respective PhD studies by the University of Waikato in New Zealand. We also thank our PhD supervisors Associate Professor Chris Eames, Dr Laura Gurney and Dr Elizabeth Reinsfield for their feedback, and the participants of our respective research projects for their involvement in our research.

Financial Support. This research received no specific grant from any funding agency, commercial, or not-for-profit sectors.

Conflict of Interest. No potential conflict of interest was reported by the authors.

\section{References}

Baker, T., \& McGuirk, P. (2017). Assemblage thinking as methodology: Commitments and practices for critical policy research. Territory, Politics, Governance, 5(4), 425-442.

Barad, K. (2007). Meeting the universe halfway: Quantum physics and the entanglement of matter and meaning. Duke University Press.

Barret, D. (2018). The history of student activism in the United States. Teen Vogue, Retrieved from, https://www.teenvogue. $\mathrm{com} /$ story/the-history-of-student-activism-in-the-united-states.

Bazzul, J., \& Kayumova, S. (2016). Toward a Social Ontology for Science Education: Introducing Deleuze and Guattari's assemblages. Educational Philosophy \& Theory, 48(3), 284-299. DOI 10.1080/00131857.2015.1013016.

Bishop, R. (2019). Teaching to the North-East: Relationship-based learning in practice. Wellington, New Zealand: NZCER Press.

Blakemore, E. (2018). Youth in revolt. Five revolutions started by young activists. National Geographic.

Boylan, M. (2016). Deepening system leadership: Teachers leading from below. Educational Management Administration \& Leadership, 44(1), 57-72. DOI 10.1177/1741143213501314.

Bright, R., \& Eames, C. (2020). Climate strikes: Their value in engaging and educating secondary school students. Set: Research Information for Teachers, 3, 4-11. DOI 10.18296/set.0180.

Caron, D. (2009). It's A Vuca World!. Retrieved from https://www.slideshare.net/dcaron/its-a-vuca-world-cips-cio-march-52009-draft.

Carter, P.D. (2019). Implications for biodiversity of potentially committed global climate change (from Science and Policy). In W.L. Filho, J. Barbir \& R. Preziosi (Eds.), Handbook of climate change and biodiversity (pp. 135-149). Springer International Publishing, DOI 10.1007/978-3-319-98681-4_8.

Codd, J. (2005). Teachers as 'managed professionals' in the global education industry: The New Zealand experience. Educational Review, 57(2), 193-206.

Cutter-Mackenzie-Knowles, A., Lasczik, A., Wilks, J., Logan, M., Turner, A., \& Boyd, W. (2019). Touchstones for deterritorializing socioecological learning: The anthropocene, posthumanism and common worlds as creative Milieux. Springer International Publishing AG, DOI 10.1007/978-3-030-12212-6.

DeLanda, M. (2006). A new philosophy of society: Assemblage theory and social complexity. Continuum.

DeLanda, M. (2013). Intensive science and virtual philosophy. Bloomsbury Publishing.

DeLanda, M. (2016). Assemblage theory. Edinburgh University Press.

Deleuze, G. (1988). Spinoza: Practical philosophy. City Lights Books.

Deleuze, G., \& Guattari, F. (1977). Anti-Oedipus: Capitalism and schizophrenia. Viking Press.

Deleuze, G., \& Guattari, F. (2004). A thousand plateaus: Capitalism and schizophrenia. Continuum.

Ellenzweig, S. (2017). The new politics of materialism: History, philosophy, science. London: Taylor \& Francis Group, 1-328, DOI 10.4324/9781315268477.

Fernández-Llamazares, Á., Lepofsky, D., Lertzman, K., Armstrong, C.G., Brondizio, E.S., Gavin, M.C., ... Vaughan, M.B. (2021). Scientists' warning to humanity on threats to indigenous and local knowledge systems. Journal of Ethnobiology, 41(2), 144-169. DOI 10.2993/0278-0771-41.2.144.

Fox, N.J., \& Alldred, P. (2015). Inside the research-assemblage: New materialism and the micropolitics of social inquiry. Sociological Research Online, 20(2), 1-19. 
Fox, N.J., \& Alldred, P. (2016). Sociology and the new materialism: Theory, research, action. Sage Publications.

Fox, N.J., \& Alldred, P. (2020). Re-assembling climate change policy: Materialism, posthumanism, and the policy assemblage. The British Journal of Sociology, 71(2), 269-283. DOI 10.1111/1468-4446.12734.

Gilbert, J. (2015). Leading in collaborative, complex education systems, Leadership for communities of learning -Five think pieces. Education Council, https://teachingcouncil.nz/assets/Files/Leadership-Strategy/Leadership-for-Communities-ofLearning-Five-Think-Pieces.pdf.

Glasgow, B. (2019). SDG workshop on climate change with young leaders and the Auckland Climate Action Framework.

Glynn, T. (2015). Bicultural challenges for educational professionals in Aotearoa. 20th Anniversary Collection, 103-113. DOI 10.15663/wje.v20i3.227.

Gordon, H.R. (2010). We fight to win: Inequality and the politics of youth activism. New Brunswick, NJ: Rutgers University Press.

Gordon, L. (1992). Educational Reform in New Zealand: Contesting the role of the teacher. International Studies in Sociology of Education, 2(1), 23-42. DOI 10.1080/0962021920020102.

Haraway, D.J. (2018).Modest_Witness@Second_Millennium.FemaleMan_Meets_OncoMouse: Feminism and technoscience. 2nd ed, Routledge, https://www.taylorfrancis.com/books/9780203731093.

IPCC. (2018). Global warming of $1.5^{\circ} \mathrm{C}$. Retrieved from http://www.ipcc.ch/report/sr15/.

Irwin, R. (2020). Climate change and education. Educational Philosophy and Theory, 52(5), 492-507. DOI 10.1080/00131857. 2019.1642196.

Jones, C.A., \& Davison, A. (2021). Disempowering emotions: The role of educational experiences in social responses to climate change. Geoforum, 118(2), 190-200. DOI 10.1016/j.geoforum.2020.11.006.

Kessel, C.V. (2020). Teaching the climate crisis: Existential considerations. Journal of Curriculum Studies Research, 2(1), 129-145. DOI 10.46303/jcsr.02.01.8.

Kwauk, C. (2020). Roadblocks to quality education in a time of climate change. Center for Universal Education at the Brookings Institution, https://eric.ed.gov/?id=ED607008.

Meyer, L.H., Penetito, W., Hynds, A., Savage, C., Hindle, R., \& Sleeter, C. (2010). Evaluation of Te Kōtahitanga, 2004-2008: Summary. Ministry of Education New Zealand.

Ministry for the Environment (2007). Consultation with Maori on climate change: Hui report. Ministry for the Environment, Retrieved from, https://www.mfe.govt.nz/sites/default/files/consultation-maori-hui-report-nov07.pdf.

Ministry of Education. (2013). Why the future focus principle is important. The New Zealand Curriculum online. Retrieved from https://nzcurriculum.tki.org.nz/Curriculum-resources/Media-gallery/Future-focus/Why-future-focus.

Ministry of Education. (2015). The New Zealand Curriculum. Retrieved from https://nzcurriculum.tki.org.nz/The-NewZealand-Curriculum.

Ministry of Education. (2021). Evaluation of Te Kōtahitanga Phase 5 (2010-2012). Retrieved from https://www. educationcounts.govt.nz/publications/schooling2/workforce/evaluation-of-te-kotahitanga-phase-5.

Murphy, P.D. (2021). Speaking for the youth, speaking for the planet: Greta Thunberg and the representational politics of eco-celebrity. Popular Communication, 19(3), 193-206. DOI 10.1080/15405702.2021.1913493.

Nairn, K. (2019). Learning from young people engaged in climate activism: The potential of collectivizing despair and hope. Young, 27(5), 435-450. DOI 10.1177/1103308818817603.

Nash, R. (1990). Bourdieu on education and social and cultural reproduction. British Journal of Sociology of Education, 11(4), 431-447. DOI 10.1080/0142569900110405.

Naufahu, M. (2018). A Pasifika research methodology: Talaloto. Waikato Journal of Education (Online), 23(1), 15-24. DOI 10.15663/wje.v23i1.635.

O'Brien, K.L. (2016). Climate change and social transformations: Is it time for a quantum leap? Wiley Interdisciplinary Reviews: Climate Change, 7(5), 618-626. DOI 10.1002/wcc.413.

Orange, C. (2021). The Treaty of Waitangi /Te Tiriti o Waitangi. Bridget Williams Books.

Reid, A. (2019). Climate Change Education and research: Possibilities and potentials versus problems and perils? Environmental Education Research, 25(6), 767-790. DOI 10.1080/13504622.2019.1664075.

Ripple, W.J., Wolf, C., Newsome, T.M., Barnard, P., \& Moomaw, W.R. (2019). World scientists' warning of a climate emergency. BioScience.

Schellnhuber, H.J., Serdeczny, O.M., Adams, S., Köhler, C., Magdalena Otto, I., \& Schleussner, C.-F. (2016). The challenge of a $4^{\circ} \mathrm{C}$ world by 2100 . In H.G. Brauch, .A.;.O. Spring, J. Grin \& J. Scheffran (Eds.), Handbook on sustainability transition and sustainable peace (pp. 267-283). Springer International Publishing, 10.1007/978-3-319-43884-9_11

Shields, C.M. (2013). Transformative leadership in education: Equitable change in an uncertain and complex world. Eye on Education, DOI 10.4324/9780203814406.

Snowden, D.J., \& Boone, M.E. (2007). A leader's framework for decision making. Harvard Business Review, 85(11), 68.

St. Pierre, E.A. (2018). Writing post qualitative inquiry. Qualitative Inquiry, 24(9), 603-608. DOI 10.1177/ 1077800417734567.

Staufenberg, J. (2019). Teacher rebellion: How Mr Jones gave up his job to fight the climate crisis. The Guardian, https://www. theguardian.com/education/2019/dec/10/teacher-rebellion-gave-up-job-fight-climate-crisis. 
Steffen, W., Rockström, J., Richardson, K., Lenton, T.M., Folke, C., Liverman, D., \& Schellnhuber, H.J. (2018). Trajectories of the earth system in the anthropocene. Proceedings of the National Academy of Sciences of the United States of America, 115(33), 8252-8259. DOI 10.1073/pnas.1810141115.

Stevenson, R.B., Nicholls, J., \& Whitehouse, H. (2017). What is Climate Change Education? Curriculum Perspectives, 37(1), 67-71. DOI 10.1007/s41297-017-0015-9.

Swyngedouw, E. (2013). Apocalypse now! Fear and doomsday pleasures. Capitalism Nature Socialism, 24(1), 9-18. DOI 10. 1080/10455752.2012.759252.

Talwar, S. (2021). Culturally mediated perceptions of climate change risks in New Zealand. Climatic Change, 164(1), 12. DOI 10.1007/s10584-021-02966-9.

Tunks, A. (1997). Tangata Whenua ethics and climate change. New Zealand Journal of Environmental Law, 1, 67-124.

UNESCO (1975). The Belgrade charter: A framework for Environmental Education. UNESCO, https://unesdoc.unesco.org/ ark:/48223/pf0000017772.

Verlie, B. (2017). Rethinking climate education: Climate as entanglement. Educational Studies, 53(6), 560-572. DOI 10.1080/ 00131946.2017 .1357555 .

Verlie, B. (2018). From action to intra-action? Agency, identity and 'goals' in a relational approach to Climate Change Education. Environmental Education Research, 1-15.

Webb, J., Schirato, T., \& Danaher, G. (2020). Understanding Bourdieu. Routledge.

Wilks, J., Turner, A., \& Shipway, B. (2019). The risky socioecological learner. In A. Cutter-Mackenzie-Knowles, A. Lasczik, J. Wilks, M. Logan, A. Turner \& W. Boyd (Eds.), Touchstones for deterritorializing socioecological learning: The anthropocene, posthumanism and common worlds as creative Milieux (pp. 75-97). Springer International Publishing AG. DOI 10.1007/978-3-030-12212-6.

Zembylas, M. (2017). The contribution of the ontological turn in education: Some methodological and political implications. Educational Philosophy and Theory, 49(14), 1401-1414. DOI 10.1080/00131857.2017.1309636.

Thomas Everth is a PdH candidate at the University of Waikato. He obtained a master's degree in Physics in Germany. After a career in the IT industry, Thomas settled in New Zealand and became a teacher. He has been teaching Physics, Mathematics, IT and Earth and Space Science at high school. Thomas is currently undertaking research in Climate Change Education and is especially interested in posthumanist ontology and the relationship of society with the more-than-human world.

Ria (Maria) Bright is an EdD candidate at the University of Waikato and a secondary school teacher from Northland, Aotearoa New Zealand. She is researching what educators may learn from the 2019 climate strikes to improve engagement and pedagogies around climate change and sustainability education. Ria also facilitates an experiential learning programme for local schools to increase an understanding of kaitiaki (guardianship) and ecological restoration.

Cite this article: Everth, T., \& Bright, R. (2023). Climate change and the assemblages of school leaderships. Australian Journal of Environmental Education 39, 17-36. https://doi.org/10.1017/aee.2022.8 